PAPER • OPEN ACCESS

\title{
Cyanide recombination in electric arc furnace plasma
}

To cite this article: Henri Pauna et al 2021 Plasma Res. Express 3025008

View the article online for updates and enhancements. 


\section{Plasma Research Express}

\section{PAPER}

CrossMark

\section{Cyanide recombination in electric arc furnace plasma}

\section{OPEN ACCESS}

RECEIVED

10 November 2020

REVISED

8 April 2021

ACCEPTED FOR PUBLICATION

27 April 2021

PUBLISHED

12 May 2021

Original content from this work may be used under the terms of the Creative

Commons Attribution 4.0 licence.

Any further distribution of this work must maintain

attribution to the

author(s) and the title of

the work, journal citation and DOI.

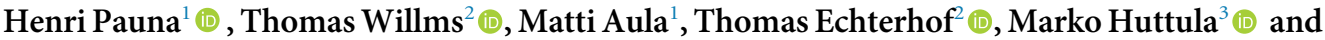 \\ Timo Fabritius ${ }^{1}$ (1) \\ 1 Process Metallurgy Research Unit, P.O. Box 4300, FI-90014, University of Oulu, Finland \\ 2 RWTH Aachen University, Department of Industrial Furnaces and Heat Engineering, Kopernikusstrasse 10, 52074 Aachen, Germany \\ 3 Nano and Molecular Systems Research Unit, P.O. Box 3000, FI-90014, University of Oulu, Finland \\ E-mail: henri.pauna@oulu.fi
}

Keywords: Electric arc furnace, Optical emission spectroscopy, Plasma, Cyanide, Off-gas

\begin{abstract}
Cyanide, among with $\mathrm{NO}_{x}, \mathrm{CO}_{2}$, and $\mathrm{CO}$, is one of the adverse compounds that form in the ironmaking and steelmaking industry. High-temperature processes are suitable environments for cyanide formation, and cyanide can form as a result of recombination in electric arc plasma. Even though the cyanides might not survive e.g. the post-combustion process, understanding the formation mechanisms of hazardous materials in the steelmaking industry is important. In this work, the recombination of cyanide in a pilot-scale AC electric arc furnace is studied with optical emissions from the $\mathrm{CN}$ molecule. The results show how the optical emissions from the cyanide change in different process steps. Electric input, plasma temperature, and interaction of the arc with solid charge material were observed to have an impact on the $\mathrm{CN}$ signal. Additionally, equilibrium composition computation highlights how different sources of carbon change the recombination rate and that the highest recombination occurs at $6821 \mathrm{~K}$.
\end{abstract}

\section{Introduction}

Cyanide (CN) and cyanide compounds, such as $\mathrm{HCN}, \mathrm{KCN}$, and $\mathrm{NaCN}$, are a subject of major concern in the iron and steel industry due to their toxicity [1-3]. Cyanide forms in flames and high-temperature environments via several possible reaction routes involving e.g. $\mathrm{C}_{2}, \mathrm{~N}_{2}, \mathrm{C}$, and $\mathrm{CH}$ [4]. The cyanides are typically located in the effluents $[2,3,5,6]$ and leachates [7] in industrial processes. The sources of carbon and nitrogen in these reactions can be the atmosphere inside the furnace, charge material, additive materials, and gas or coke injections. The permissible amount of cyanide in disposed water is strictly defined [1], and this limit in the effluents is usually around $0.20 \mathrm{mg} /$ litre or less [1,5-7].

Industrial electric arc furnaces (EAFs) and ladle furnaces (LFs) do not usually have water scrubbers, which means that cyanide is not a problem in the effluents. Submerged arc furnaces, on the other hand, may have a problem with the cyanide content [8]. Since a high-temperature environment is favorable for cyanide formation, it most probably is present in the industrial EAF and LF atmosphere to some extent even though it might not survive through the post-combustion process. Furthermore, post-combustion might not be implemented in semi-industrial EAFs with a capacity of only several hundred kilograms. Eventually, monitoring the formation of any hazardous gases would be beneficial e.g. in case a malfunction occurs in any process that aims to decompose harmful compounds.

A method that is viable for in situ analysis in industrial EAF and LF conditions is optical emission spectroscopy (OES). Generally, observations of molecular optical emission bands from the $\mathrm{CN}$ have been widely reported in various fields of applied spectroscopy, such as laser-induced breakdown spectroscopy (LIBS) studies of solid materials containing $\mathrm{C}$ and $\mathrm{N}$ [9], benzene and carbon disulfide [10], together with optical spectroscopy of plasmas including polyvinyl chloride [11], graphite [12], carbon nanotubes [13], and electrical discharge assisted combustion [14]. In LIBS studies, molecular emission bands of $\mathrm{CN}$ have also been used to derive the carbon content of steel [15], fly ash [16], and coal [17]. Related to steelmaking, cyanide has been suggested to have an effect on the reduction of $\mathrm{Fe}_{2} \mathrm{O}_{3}$ in a spectroscopic analysis including microwave treatment [18]. 

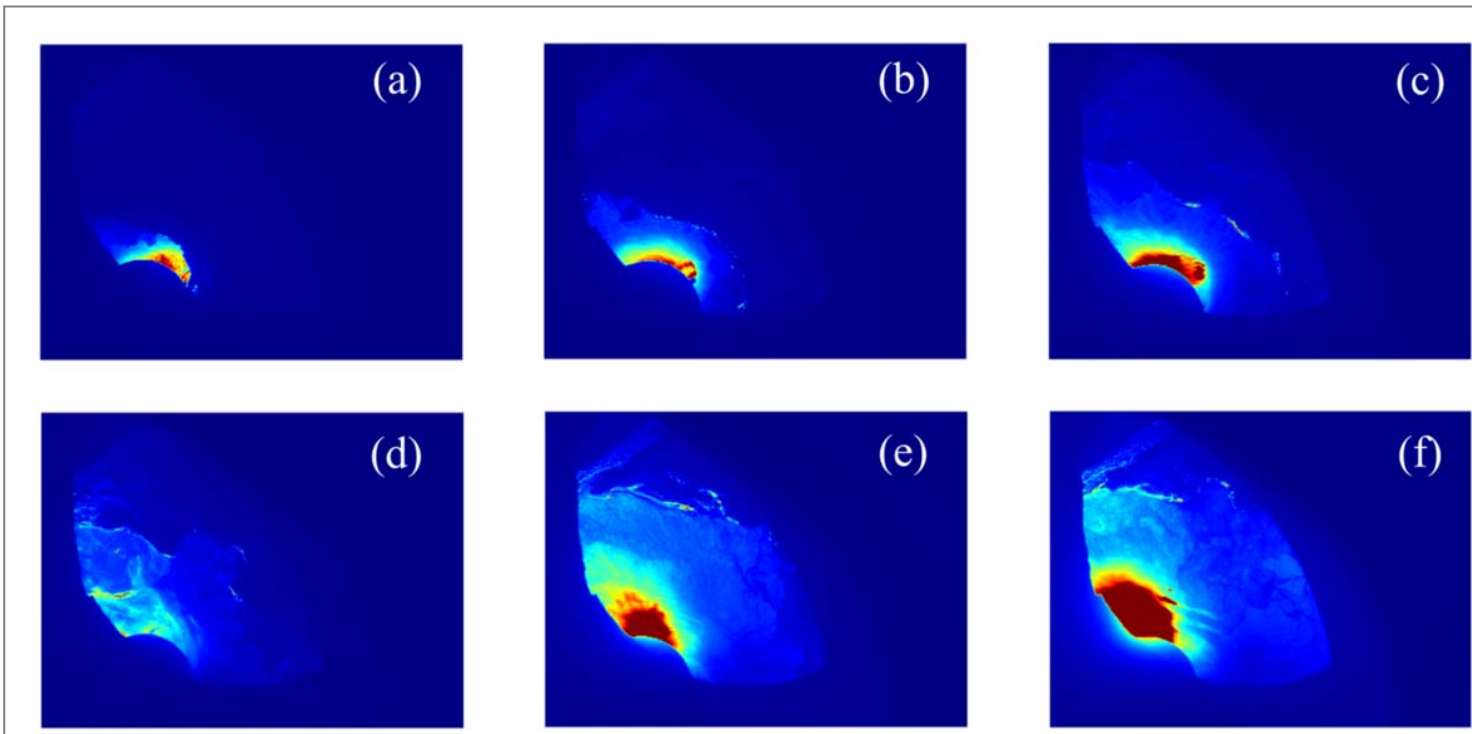

Figure 1. Top-view of the time-evolution of melting during one heat with chronological order from (a) to (f).

Due to easily identifiable optical emission band structure, the optical emission spectroscopic studies of CN offer a practical analysis method that is viable also for online applications in EAFs and LFs. In this work, the optical emissions from the $\mathrm{CN}$ molecule were studied during pilot-scale AC EAF process steps. The purpose of the study was to investigate the changes in the $\mathrm{CN}$ signal during different process steps, which may contain information on the formation and concentration of cyanide inside the furnace. The OES data has been analyzed and compared to the electrical data of the furnace, off-gas analysis of $\mathrm{CO}_{2}, \mathrm{O}_{2}$, and $\mathrm{H}_{2}$, and camera footage.

\section{Methods and materials}

The measurements were conducted at RWTH Aachen University, Germany. The pilot-scale furnace has two graphite electrodes with $10 \mathrm{~cm}$ diameter, and $200 \mathrm{~kg}$ liquid steel capacity. The voltage, current, and power of one electrode were recorded once every two seconds. The active power is $600 \mathrm{~kW}$ with an arc current maximum of $2000 \mathrm{~A}$. The apparent power of the transformer is $850 \mathrm{kVA}$. Six heats were performed during the measurement campaign. Before each heat, additive materials were charged into the furnace. The slag surface, which forms on top of the molten bath from the impurities of the charge material and additive materials, consists of $\mathrm{CaO}, \mathrm{MgO}$, $\mathrm{MnO}, \mathrm{Cr}_{2} \mathrm{O}_{3}, \mathrm{Fe}_{2} \mathrm{O}_{3}, \mathrm{SiO}_{2}$, and $\mathrm{Al}_{2} \mathrm{O}_{3}$. These components are common constituents of industrial slags. The additive materials consisted of varying amounts of $\mathrm{CaO}, \mathrm{MgO}, \mathrm{SiO}_{2}, \mathrm{Al}_{2} \mathrm{O}_{3}$, and slag from the industrial furnace. The off-gas components $\mathrm{CO} 2, \mathrm{O} 2$, and $\mathrm{H} 2$ were continuously detected with the rate of $1 \mathrm{~Hz}$. The furnace operates at ambient pressure, except for the negative pressure of the dedusting system around $-4 \mathrm{mbar}$.

A Baumer single-lens reflex camera was used to record the movements of the electric arc and melting of the solid material. The frame rate of the camera was 10 images per second. The camera was filtered with three green light band-pass filters that are used in welding. The spectrometers and camera were positioned on top of the furnace and looked into the furnace through an opening in the furnace roof. This represents the probable case in an industrial electric arc furnace, where the measurement heads could be attached to the roof [19]. Figure 1 displays the time-evolution of the melting of the charge material during one heat. The images have been converted from red-green-blue (RGB) to grayscale. The standard RGB pixel brightness values range from 0 to 255,0 being the dimmest and 255 the brightest.

Czerny-Turner Avaspec-ULS2048 spectrometers were used in this study. The spectrometers covered $247.337-419.199 \mathrm{~nm}$ and $496.655-1000.000 \mathrm{~nm}$. These spectrometers are referred to as UV and NIR, respectively. For each spectrometer, 16 spectra were recorded in a second. In order to correlate the spectrum data with the off-gas and electrical data, the brightest spectra measured during each second were used in the analysis. Example spectra are presented in figure 2. The spectra are dominated by optical emission lines from iron, calcium, chromium, aluminum, silicon, magnesium, and manganese, together with potassium, sodium, and lithium [19-23]. The emission lines from the slag components did not significantly overlap with the $\mathrm{CN}$, carbon, nitrogen, oxygen, or hydrogen optical emission lines that were used in this study.

At the beginning of the measurements, a batch of charge material was melted for an hour to form the molten bath. This initial melting period has been used to observe how the optical emissions from $\mathrm{CN}$ behave when the furnace conditions are close to the early stages of the EAF process, namely ignition, boring, and formation of 


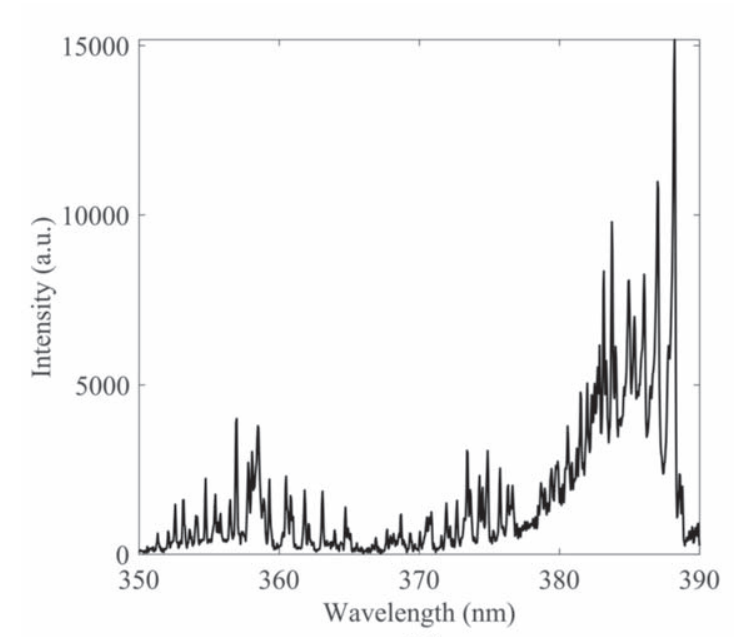

(a)

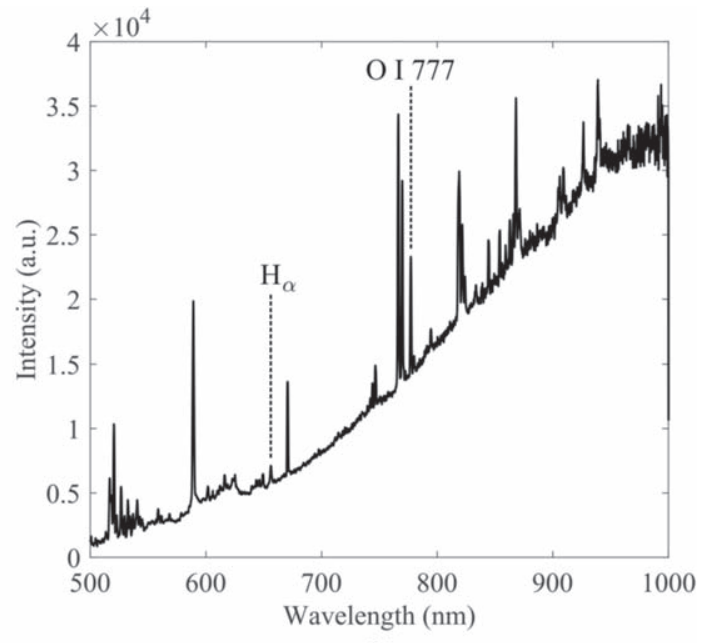

(b)

Figure 2. Spectra between (a) 350 and $390 \mathrm{~nm}$ showing the $\mathrm{CN}$ violet system and several atomic optical emissions and (b) 600 and $900 \mathrm{~nm}$ showing optical emissions from slag components together with C I, N I, O I, and H I. O I at $777 \mathrm{~nm}$ and $\mathrm{H}_{\alpha}$ have been marked to the spectrum.

melt. After this initial melting period, the view into the furnace was clear, and also the camera was turned on. This measurement period, on the other hand, represents the main heating period, charging of additional material, and flat bath period of the EAF process. The EAF was turned off momentarily when additive materials were charged into the furnace. Sometimes a protective shutter was placed in the view cone of the spectrometers and camera when the EAF was off.

\section{Theoretical}

In comparison with atomic emission lines, molecular emission spectra are more complicated due to vibrational and rotational energy states of the molecule [24]. The effect of rotational energy states was not observed in this study due to their relatively small effect on the spectra, whereas vibrational transitions are more notable and were clearly observed in the $\mathrm{CN}$ molecule. A pure electronic transition that does not include vibrational energy states is denoted (0-0), where the first zero refers to the excited energy state from which the electron decays to the energy state denoted by the second zero. Transitions including vibrational state or states are denoted (1-0), $(0-1),(1-1)$, etc. The observed CN, O I, H I, N I, and C I emission lines are listed in table 1 . The Roman numeral I refers to a neutral atom. The $\mathrm{CN}$ violet system is in the $\mathrm{UV}$ region between $350 \mathrm{~nm}$ and $450 \mathrm{~nm}$, whereas the most intensive O I, H I, N I, and C I emission lines were observed to reside in the visible or near-infrared wavelength ranges. In order to remove the effect of varying arc visibility due to erratic movement of the arc on slag and solid charge partially blocking the view cone, the $\mathrm{CN}$ intensities have been divided with the average value of the spectrum intensity. The average intensity of the spectrum is automatically determined during spectrum acquisition.

Due to the high energy of the arc, plasma diagnostics can be used to analyze the OES data. The temperature of the plasma was determined with the Boltzmann equation [27]

$$
\ln \left(\frac{\epsilon^{z} \lambda_{m n}}{g_{m} A_{m n}}\right)=-\frac{1}{k T} E_{m}^{z}+\ln \left(\frac{h c N^{z}}{4 \pi U^{z}(T)}\right)
$$

where $z$ is ionization state of the particle, $\epsilon^{z}$ is wavelength-integrated emissivity $n$ is lower atomic energy state, $m$ is upper atomic energy state, $\lambda_{m n}$ is wavelength of the emission line, $g_{m}$ is degeneracy of the upper atomic energy state, $A_{m n}$ is transition probability, $k$ is the Boltzmann constant, and $T$ is the plasma temperature, $\mathrm{E}_{\mathrm{m}}^{\mathrm{z}}$ is energy of the upper atomic energy state, $N^{z}$ is number density, and $U^{z}(T)$ is partition function. At a fixed temperature, the term containing the partition function is constant and can be neglected when the left-hand-side of equation (1) is plotted with respect to $\mathrm{E}_{\mathrm{m}}^{\mathrm{z}}$. The plasma temperature can thus be solved from the slope of the plot. 
Table 1. List of observed CN, N, C, O, and H emission lines.

\begin{tabular}{|c|c|c|c|}
\hline Line & $\lambda(\mathrm{nm})$ & Line & $\lambda(\mathrm{nm})$ \\
\hline $\mathrm{CN}(0-0)[9,10,12,25]$ & 388.34 & $\mathrm{NI}[26]$ & 744.23 \\
\hline $\mathrm{CN}(1-1)[9,10,12,25]$ & 387.14 & $\mathrm{NI}[26]$ & 746.83 \\
\hline $\mathrm{CN}(2-2)[9,10,12,25]$ & 386.19 & N I [26] & 818.49 \\
\hline $\mathrm{CN}(3-3)[9,10,12,25]$ & 385.47 & N I [26] & 818.80 \\
\hline $\mathrm{CN}(4-4)[9,10,12,25]$ & 385.09 & N I [26] & 820.04 \\
\hline $\mathrm{CN}(5-5)[25]$ & $\approx 384.90$ & N I [26] & 821.07 \\
\hline $\mathrm{CN}(1-0)[9,10,12]$ & 359.00 & N I [26] & 821.63 \\
\hline $\mathrm{CN}(2-1)[9,10,12]$ & 358.58 & N I [26] & 822.31 \\
\hline $\mathrm{CN}(3-2)[9,10,12]$ & $\approx 358.40$ & N I [26] & 824.24 \\
\hline $\mathrm{CN}(4-3)[12]$ & $\approx 358.40$ & N I [26] & 856.77 \\
\hline $\mathrm{CN}(2-3)[10,12]$ & $\approx 418.00$ & N I [26] & 859.40 \\
\hline $\mathrm{CN}(3-4)[10,12]$ & $\approx 416.70$ & N I [26] & 862.92 \\
\hline $\mathrm{CN}(4-5)[10,12]$ & $\approx 415.80$ & N I [26] & 868.03 \\
\hline $\mathrm{CN}(5-6)[10]$ & $\approx 415.10$ & N I [26] & 868.34 \\
\hline CI [26] & 906.14 & $\mathrm{~N} \mathrm{I}[26]$ & 868.62 \\
\hline CI [26] & 906.25 & N I [26] & 870.33 \\
\hline CI [26] & 907.83 & N I [26] & 871.17 \\
\hline CI [26] & 908.85 & N I [26] & 871.88 \\
\hline C I [26] & 909.38 & N I [26] & 872.89 \\
\hline CI [26] & 911.18 & & \\
\hline OI [26] & 777.42 & & \\
\hline OI [26] & 844.68 & & \\
\hline O I [26] & 926.09 & & \\
\hline OI [26] & 926.60 & & \\
\hline $\mathrm{HI}\left(\mathrm{H}_{\alpha}\right)[26]$ & 656.28 & & \\
\hline
\end{tabular}

Table 2. List of O I lines used in plasma temperature analysis.

\begin{tabular}{lcccc}
\hline Line & $\lambda_{m n}(\mathrm{~nm})$ & $\mathrm{A}_{m n}\left(\mathrm{~s}^{-1}\right)$ & $\mathrm{E}_{m}^{z}(\mathrm{eV})$ & $\mathrm{g}_{m}$ \\
\hline OI[26] & 777.42 & $3.69 \mathrm{e}+07$ & 10.74 & 5 \\
O I[26] & 844.68 & $3.22 \mathrm{e}+07$ & 10.99 & 3 \\
OI[26] & 926.09 & $1.56 \mathrm{e}+07$ & 12.08 & 5 \\
OI[26] & 926.60 & $4.45 \mathrm{e}+07$ & 12.08 & 9 \\
\hline
\end{tabular}

The errors of the plasma temperatures can be obtained with

$$
\frac{\delta T}{T}=\frac{k T}{\left[\sum_{i=1}^{q} E_{i}^{2}-\frac{1}{q}\left(\sum_{i=1}^{q} E_{i}\right)^{2}\right]^{1 / 2}}\left(\frac{\delta \epsilon}{\epsilon}+\frac{\delta A}{A}\right),
$$

where $q$ is the number of emission lines, $\delta \epsilon / \epsilon$ is the general relative error of line intensity, and $\delta A / A$ is the general relative error of transition probability [28]. The plasma temperature was determined with four O Ilines, which are listed in table 2.

In an earlier study involving the same pilot-scale furnace under similar conditions, the plasma temperatures were determined to be within a range from 4500 to $9000 \mathrm{~K}$, electron densities between $10^{18}$ and $10^{20} \mathrm{~cm}^{-3}$, and local thermodynamic equilibrium criterion densities around $2 \times 10^{15} \mathrm{~cm}^{-3}$ [21]. The electrical properties of the arc, such as voltage gradient and anode-cathode voltage drop, together with conductivity and effect of slag composition have been discussed in another study [29].

\section{Results and discussion}

\subsection{Early stages of EAF process: ignition, boring, and formation of melt}

The time-evolution of the $\mathrm{CN}(0-0)$ intensity, the average intensity of the spectra, plasma temperature, electrical data of the furnace, and off-gas components have been presented in figure 3 for initial melting. The different $\mathrm{CN}$ transitions that are listed in table 1 have nearly exactly the same trends, so only $\mathrm{CN}(0-0)$ is presented. When the EAF is on, the $\mathrm{CO}_{2}$ is saturated at $20 \%$ which is the observation limit of the off-gas analysis system. When compared to the data of the later stages of the EAF process, the highest $\mathrm{CO}_{2}$ content is observed during this initial melting of the solid charge material. 


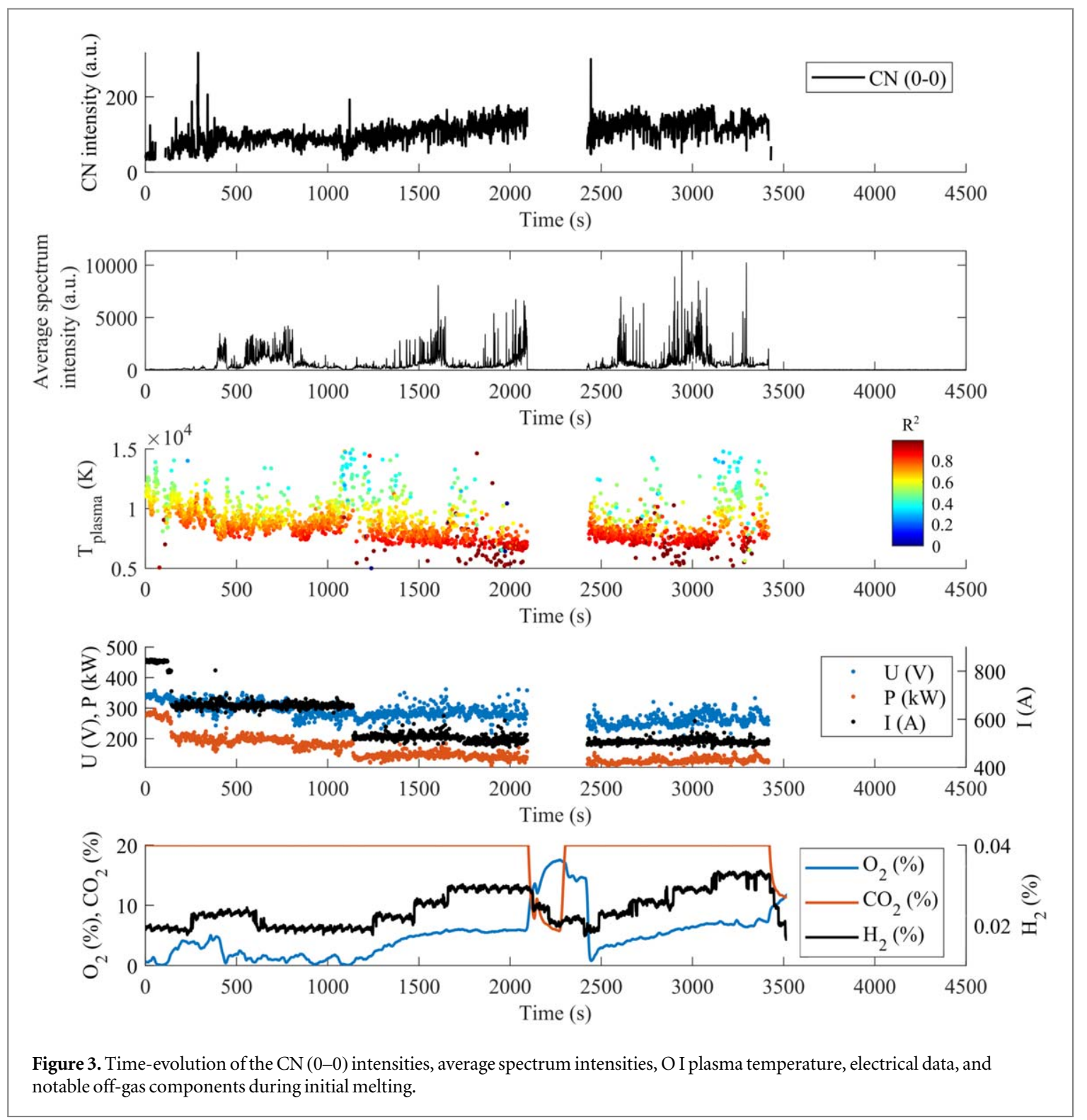

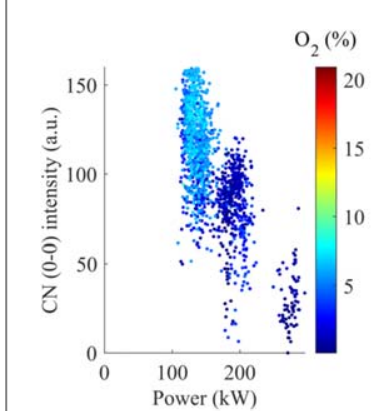

(a)

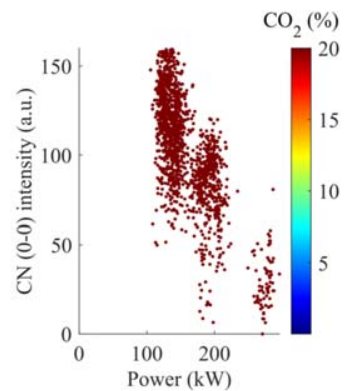

(b)

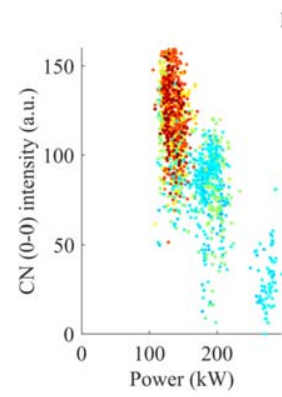

(c)

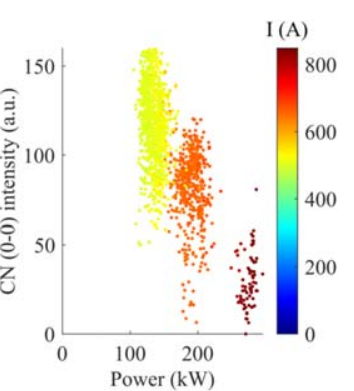

(d)

Figure 4. Relation between the power and $\mathrm{CN}(0-0)$ intensity with (a) $\mathrm{O}_{2}-\%$, (b) $\mathrm{CO}_{2}-\%,(\mathrm{c}) \mathrm{H}_{2}-\%$, and (d) current in the colorbar.

The EAF power with respect to the $\mathrm{CN}(0-0)$ intensity has been displayed in figure 4 with $\mathrm{O}_{2}, \mathrm{CO}_{2}, \mathrm{H}_{2}$, and current in the colorbars. The power values near $300 \mathrm{~kW}$ are from the very beginning of melting, which can mean that the low amount of $\mathrm{CN}$ is also related to solid charge blocking the view cone to the electric arc. The increase of CN intensities starting at 1100 s coincides with the increase in the $\mathrm{O}_{2}$, which indicates that the CN intensity starts to increase when the solid charge material has melted for the most part. At $1100 \mathrm{~s}$ also the power and current are lowered and the plasma temperatures start to decrease. 

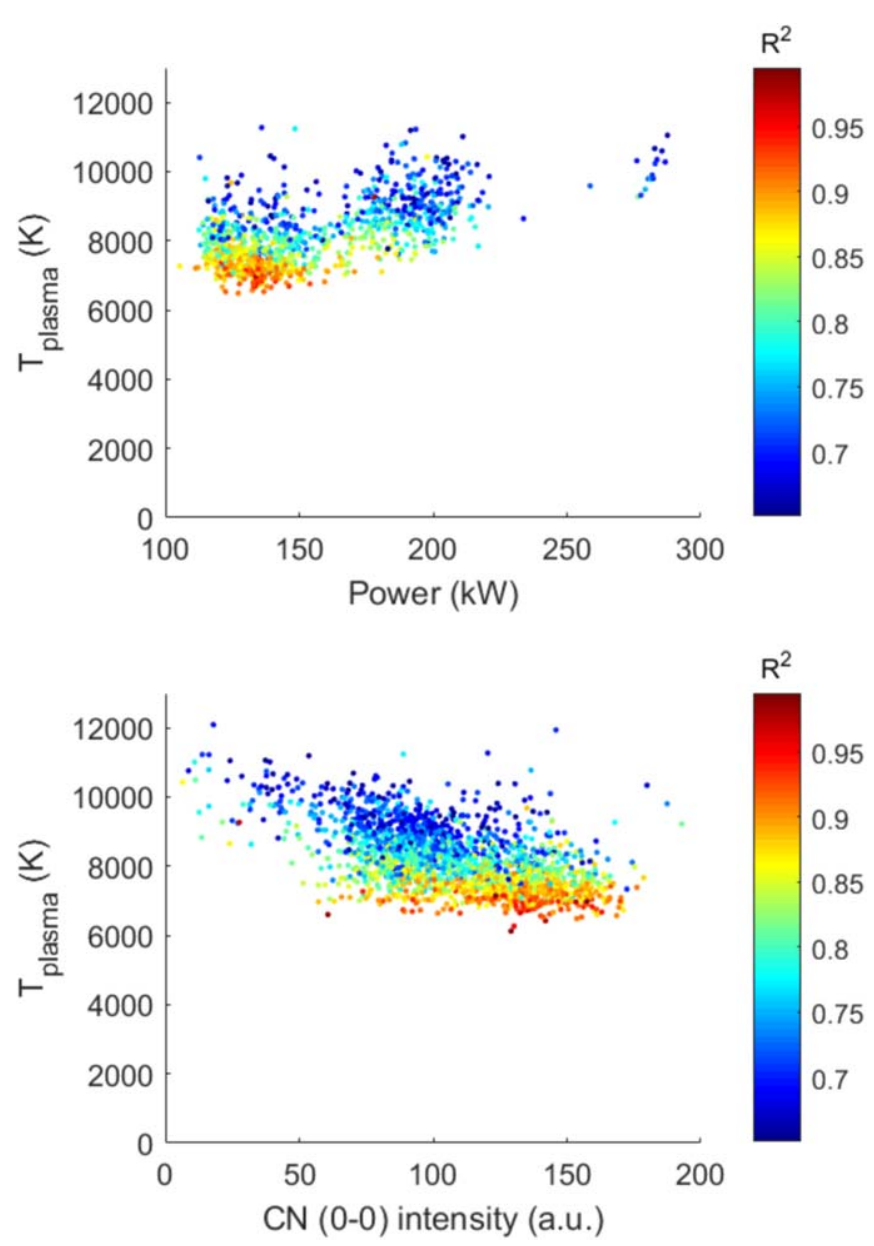

Figure 5. O I plasma temperature with respect to (a) power and (b) $\mathrm{CN}(0-0)$ intensity in the early stages of melting. The $\mathrm{R}^{2}$ of the plasma temperature fit is indicated in the colorbar.

Plasma temperature shows high fluctuation in the figure 3, ranging from 5000 to $15000 \mathrm{~K}$. The majority of $\mathrm{R}^{2}$ larger than 0.85 , however, are between 6000 and $8000 \mathrm{~K}$. Figure 5 shows crude trends between the plasma temperature, power, and $\mathrm{CN}(0-0)$ intensity. The recombination of $\mathrm{CN}$ in the plasma tends to be highest when plasma temperature is between 6000 and $8000 \mathrm{~K}$. This is also the range with the highest $\mathrm{R}^{2}$ values. Parigger et al [30] state in their LIBS study that the optical emissions from $\mathrm{CN}$ depend on the plasma temperature. In their work, the highest $\mathrm{CN}$ recombination occurs between 6000 and $9000 \mathrm{~K}$ with a maximum of around $7000 \mathrm{~K}$. On average, higher plasma temperature results to lower the $\mathrm{CN}$ intensity in figure 5 , which is in line with the results of Parigger et al for lower CN signal above $9000 \mathrm{~K}$. Furthermore, figures 4 and 5 show that higher power and current result to lower $\mathrm{CN}$ intensity, which could be explained with increasing plasma temperature when the electric input is increased.

\subsection{Later stages of EAF process: additions, main heating, and flat bath}

The time-evolution of the $\mathrm{CN}(0-0)$, average spectrum intensity, image brightness, O I plasma temperature, electrical data of the furnace, and off-gas data for $\mathrm{O}_{2}, \mathrm{CO}_{2}$, and $\mathrm{H}_{2}$ is presented in figure 6 . The plasma temperatures are within the range from 4000 to $8000 \mathrm{~K}$ with a mean $\mathrm{R}^{2}$ value of 0.93 for the Boltzmann plots and an error between 8.6 and $17.4 \%$. Between 0 and $1800 \mathrm{~s}$, it can be seen that the $\mathrm{CN}$ intensities fluctuate significantly and that the highest $\mathrm{CN}$ intensities are observed in this time period. Charge material and carbon were added into the furnace prior to the measurement of figure 6, which could further increase the formation of $\mathrm{CN}$. Because of this, the data from 0 to $1800 \mathrm{~s}$ has been presented apart from the 1800-5800 s data. It should be noted that the camera was turned on around $900 \mathrm{~s}$ in order to capture the arc movement and the slag surface when the initial charge had melted.

The relation between the $\mathrm{CN}(0-0)$ intensity and power, current, and off-gas components have been presented in figure 7, where (a) to (d) describe the melting of the charge material (0-1800 s in figure 6) and (e) to (h) the additions, main heating, and flat bath (1800-5800 s in figure 6). The relations of figures 7 (a) to (d) are very irregular when compared to the (e) to (h). Higher $\mathrm{CN}$ intensities are observed when $\mathrm{CO}_{2}$ content of the off-gas is 

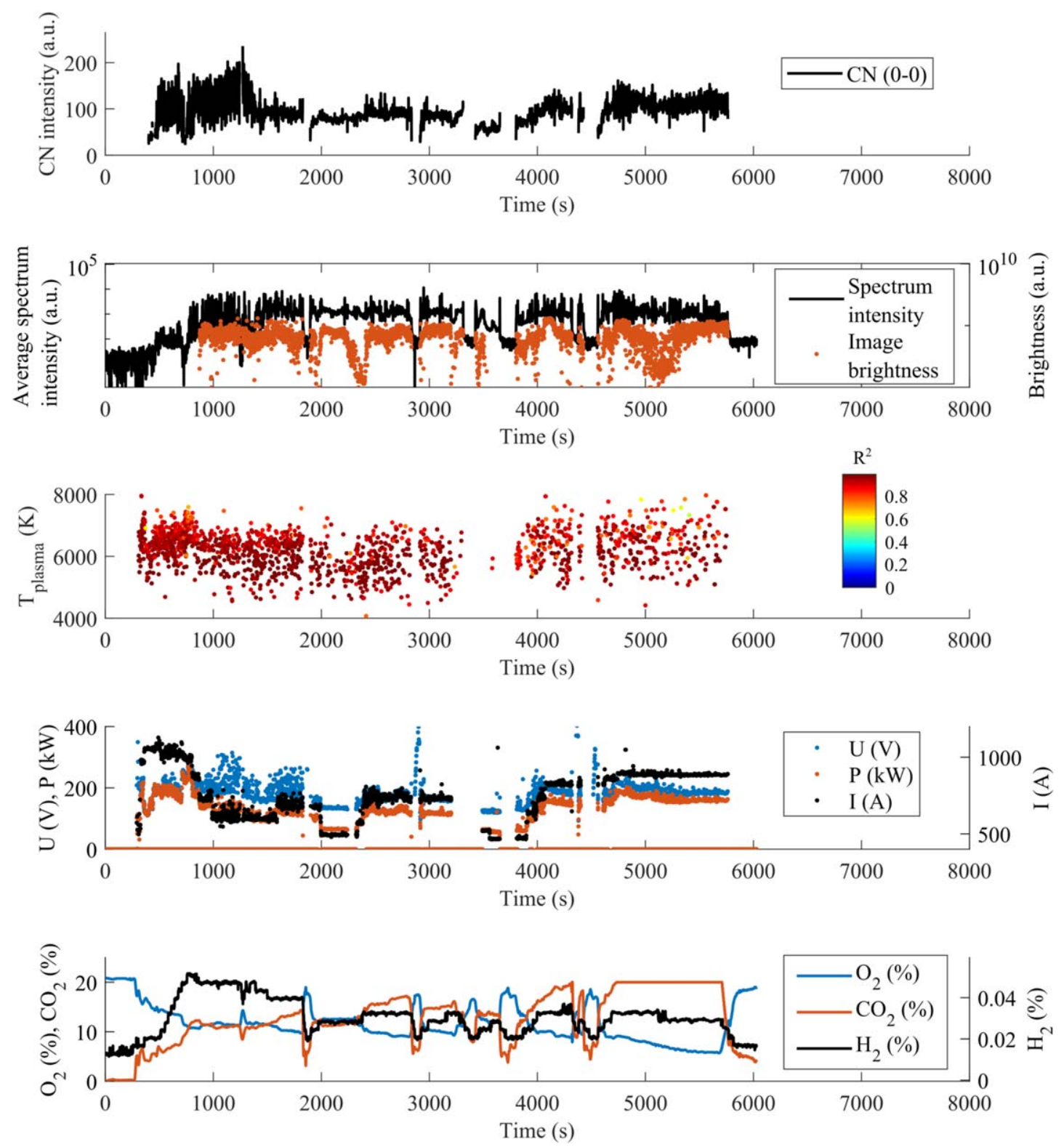

Figure 6. Time-evolution of the $\mathrm{CN}(0-0)$ intensities, O I plasma temperature, average spectrum intensity, arc image brightness, electrical data, and notable off-gas components.

between 10 and $12 \%$, i.e. the highest $\mathrm{CO}_{2}$ content in the range from 0 to $1800 \mathrm{~s}$. Figures $7(\mathrm{e})$ to (h) have more systematic trends between the power and $\mathrm{CN}$ formation where the $\mathrm{CN}$ intensities are, generally, higher with a higher power. Similar to (a) to (d), $\mathrm{CO}_{2}$ content is higher with higher $\mathrm{CN}$ intensities. It should be pointed out that between 1800 and $5800 \mathrm{~s}$ the instances of highest power and $\mathrm{CN}$ formation are observed between 4500 and 5000 s, i.e. towards the end of the measurement period.

The trends of figure 7 are very different from figure 4 . The difference in the measurement conditions between the two melting periods is that in the case of figure 4 the furnace initially has only solid charge material which is then melted, whereas in figure 7 the charge material is added on top of the molten bath. Another clear difference is in the plasma temperatures of these two cases. The majority of plasma temperatures in figure 6 fall between 5000 and $8000 \mathrm{~K}$, which is within the temperature range that Parigger et al [30] reported for CN signals. One explanation for the clearer trends in figures 7 (e) to (h) could be the lower plasma temperatures with a narrower range in comparison to figure 3 where the plasma temperatures vary from 5000 to $15000 \mathrm{~K}$. In the conditions of figures 7(e) to (f), higher power and current leads to an increase in CN intensity. The irregularity of figures 7 (a) to (d), on the other hand, can be attributed to erratic arc behavior during melting of solid charge material, where the arc moves between the solid charge material and the slag surface. This can also be seen in the voltage of figure 6 that fluctuates significantly between 1000 and $1800 \mathrm{~s}$ as the arc wanders between the molten surface and the solid charge. This time period corresponds to $\mathrm{CO}_{2}$ off-gas contents between 10 and $12 \%$ in 


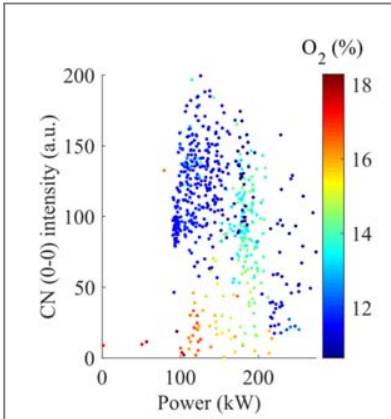

(a)

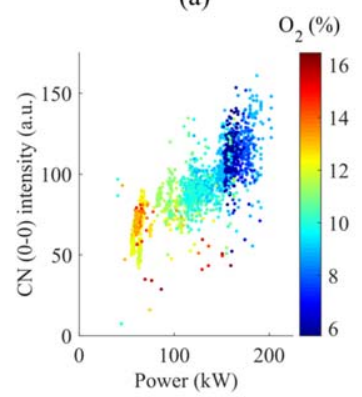

(e)

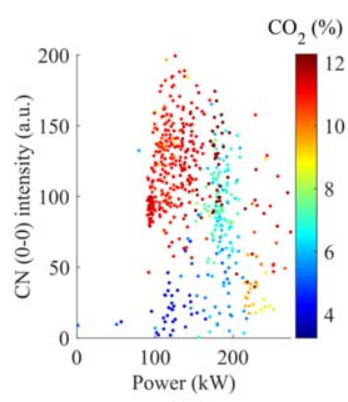

(b)

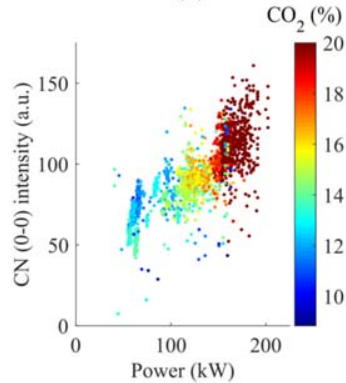

(f)

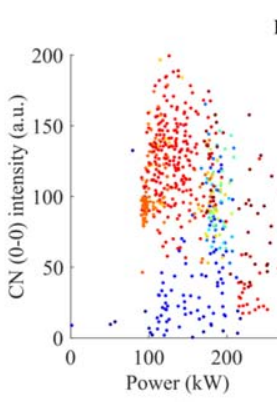

(c)

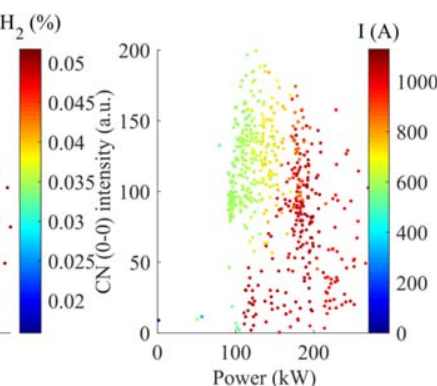

(d)

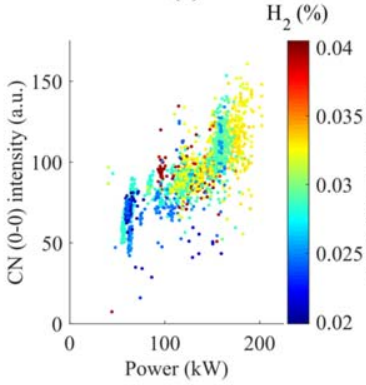

(g)

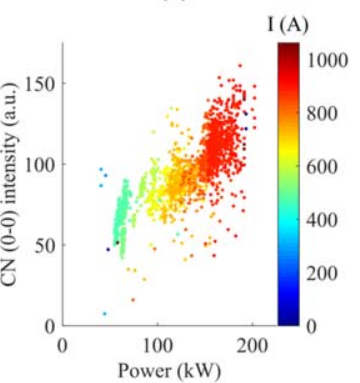

(h)

Figure 7. (a) to (d) present the relation between $\mathrm{CN}(0-0)$ intensity and power in the beginning of melting $(0-1800 \mathrm{~s}$ in figure 6), whereas $(\mathrm{e})$ to $(\mathrm{h})$ present the relation between $\mathrm{CN}(0-0)$ intensity and power during the additions, main heating, and flat bath (1800-5800 s in figure 6).

figure 7(b) and to the highest $\mathrm{CN}$ intensities. Hence, the highest $\mathrm{CN}$ intensities are observed when the arc interacts with the solid charge material.

\subsection{Equilibrium composition computation}

It was evident from the spectra that intensive $\mathrm{N}_{2}, \mathrm{O}_{2}$, and $\mathrm{C}_{2}$ optical emission bands were not observed. $\mathrm{C}_{2}$ Swan band has numerous optical emissions in the UV and visible range $[11,12,14,18]$, whereas intense $\mathrm{N}_{2}$ optical emissions can be found in the $\mathrm{UV}[13,14,18]$. The natural amount of $\mathrm{N}_{2}$ and $\mathrm{O}_{2}$ in the air suggests that these molecules are dissociated into atoms. However, the majority of $\mathrm{C}_{2}$ can be expected to originate from the molten bath or the electrode. At least from the location of the spectrometers that were used in this study, the optical emissions from the $\mathrm{C}_{2}$ could not be observed. However, $C$ I lines were observed above $800 \mathrm{~nm}$, which could mean that the $\mathrm{C}_{2}$ molecules tend to dissociate into atomic $\mathrm{C}$.

Due to the lack of $\mathrm{N}_{2}, \mathrm{O}_{2}$, and $\mathrm{C}_{2}$ optical emissions, the dissociation of air was analyzed using HSC Chemistry software made by Outotec Oyj. In order to take into account some of the impurities in the furnace atmosphere, the composition of the air entering the plasma was defined as $72.40 \% \mathrm{~N}_{2}, 24.05 \% \mathrm{O}_{2}, 0.50 \% \mathrm{H}_{2}, 0.50 \% \mathrm{CO}_{2}$, $0.50 \% \mathrm{CO}, 0.05 \% \mathrm{C}, 0.50 \% \mathrm{Ar}, 0.50 \% \mathrm{H}_{2} \mathrm{O}, 0.50 \% \mathrm{~K}$, and $0.50 \% \mathrm{Na}$. Intensive $\mathrm{K}$ I and $\mathrm{Na}$ I optical emissions can be observed whenever the EAF is turned on, which means that they could contribute to the formation of either $\mathrm{KCN}$ or $\mathrm{NaCN}$. $\mathrm{H}_{2} \mathrm{O}$ and $\mathrm{H}_{2}$ were added to the mixture in order to see if $\mathrm{HCN}$ forms in the plasma.

The results of the HSC equilibrium composition analysis have been presented in figure $8 . \mathrm{CO}_{2}$ mostly dissociates already below $4000 \mathrm{~K}$, whereas $\mathrm{CO}$ is persistent up to $6000 \mathrm{~K}$. Above $6000 \mathrm{~K}$, minor $\mathrm{C}_{2}$ recombination occurs. Contrary to $\mathrm{CO}_{2}, \mathrm{~N}_{2}$ and $\mathrm{O}_{2}$ are persistent up to $4000 \mathrm{~K}$. NO forms between 4000 and $6000 \mathrm{~K}$, where also minor $\mathrm{NO}_{2}$ formation is observed. The amount of atomic oxygen in the plasma increases already above $4000 \mathrm{~K}$, whereas atomic carbon and nitrogen start to increase around $6000 \mathrm{~K}$. Atomic optical emissions of N I, O I, and C I were observed in all spectra. Interestingly, no $\mathrm{N}_{2}$ optical emissions were observed even though the molecule is, according to the HSC calculations, present in the plasma up to $7000 \mathrm{~K}$.

The HSC calculation for recombination of the cyanide species $\mathrm{HCN}, \mathrm{NaCN}, \mathrm{KCN}$, and $\mathrm{CN}$ is presented in figure 8(d). The formation of $\mathrm{HCN}$ is the lowest, followed by $\mathrm{NaCN}$ and $\mathrm{KCN}$. The $\mathrm{CN}$ formation is several magnitudes higher than those of $\mathrm{HCN}, \mathrm{NaCN}$, and $\mathrm{KCN}$, but still only fractions of a percent. The amount of $\mathrm{Na}$ and $\mathrm{K}$ in the process depends on the charge material, and a charge material with a high alkali metal concentration might result in a higher yield of $\mathrm{NaCN}$ and $\mathrm{KCN}$. The peak of the $\mathrm{CN}$ is at $6821 \mathrm{~K}$. The chemical equilibrium computation reported by Parigger et al [30] resulted in a similar peak close to $7000 \mathrm{~K}$. In another study, they studied graphene with LIBS where the $\mathrm{CN}$ spectrum had a temperature of $6840 \mathrm{~K}$ [31]. In our study, the majority of the O I plasma temperatures with high $\mathrm{R}^{2}$ are between 4000 and $8000 \mathrm{~K}$. As can be seen from the figure 8 , the amount of atomic $\mathrm{O}$ starts to increase near $4000 \mathrm{~K}$. Recombination of $\mathrm{CN}$ is negligible at this low temperature, 


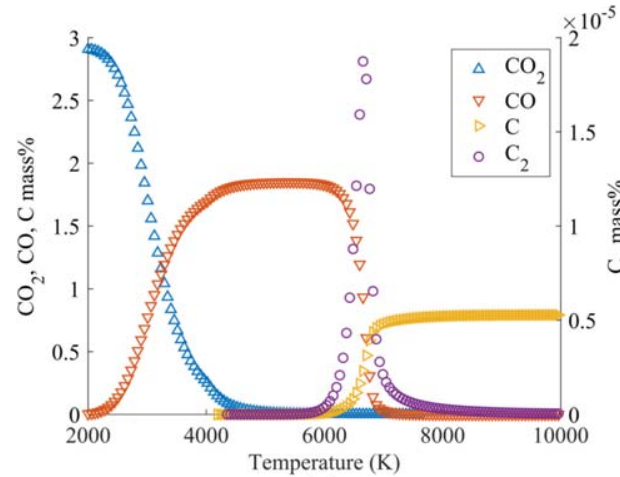

(a)

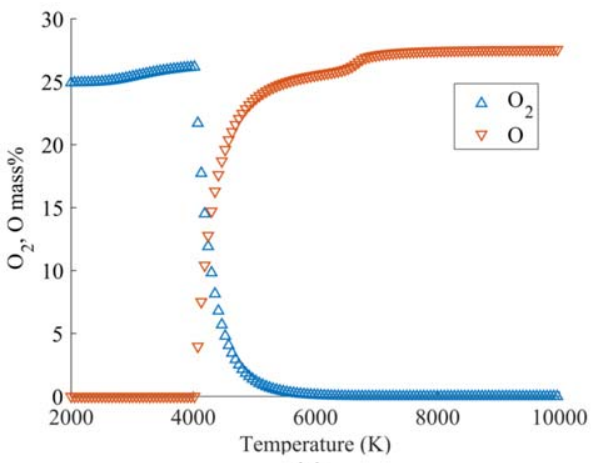

(c)

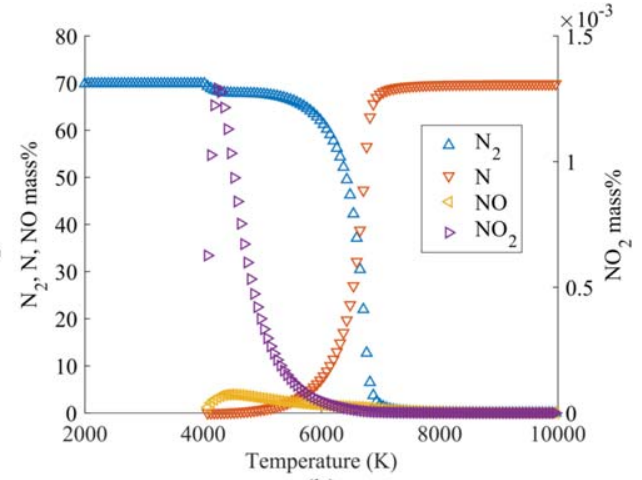

(b)

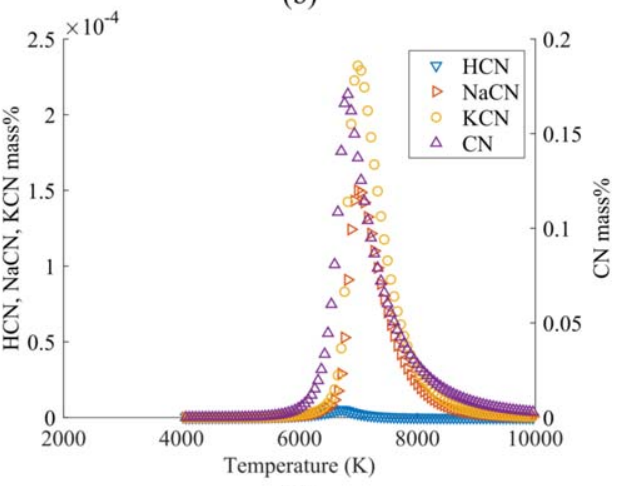

(d)

Figure 8. HSC equilibrium composition analysis for (a) $\mathrm{CO}_{2}, \mathrm{CO}, \mathrm{C}$, and $\mathrm{C}_{2}$, (b) $\mathrm{N}_{2}, \mathrm{~N}, \mathrm{NO}$, and $\mathrm{NO}_{2}$, (c) $\mathrm{O}_{2}$ and $\mathrm{O}$, and (d) $\mathrm{HCN}$, $\mathrm{NaCN}, \mathrm{KCN}$, and CN.

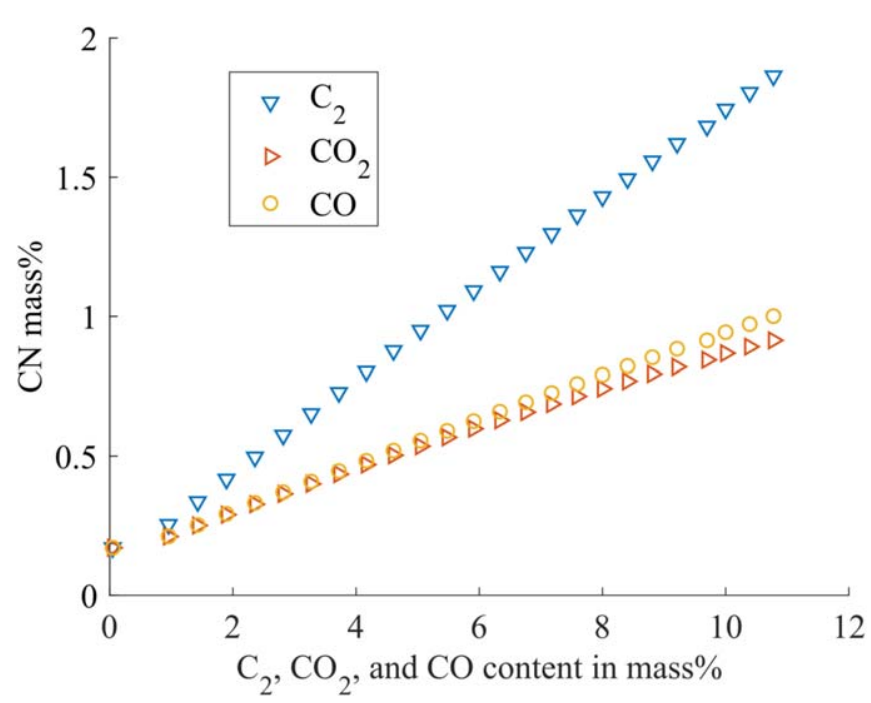

Figure 9. HSC equilibrium composition analysis for $\mathrm{C}_{2}, \mathrm{CO}_{2}$, and $\mathrm{CO}$ additions to the gas at $6821 \mathrm{~K}$.

which could mean that the $\mathrm{CN}$ recombination takes place closer to the center of the arc, where the plasma temperature is higher and reaches temperatures near and above $6000 \mathrm{~K}$.

With additional carbon input, the cyanide recombination will consequently increase. Figure 9 demonstrates how additions of $\mathrm{CO}_{2}, \mathrm{CO}$, and $\mathrm{C}_{2}$ affect the $\mathrm{CN}$ recombination at $6821 \mathrm{~K}$, which corresponds to the plasma temperature at which $\mathrm{CN}$ recombination is at its peak according to figure $8 . \mathrm{C}_{2}$ additions have the most prominent effect. The electrodes are a potential source of $\mathrm{C}_{2}$ due to the evaporation of electrode material. An increase in $\mathrm{CO}$, on the other hand, can be observed during slag foaming practice. In this work, the $\mathrm{CO}_{2}$ content of the off-gas saturated at $20 \%$, which also corresponds to the highest intensities of CN optical emissions in the 
later stages of the melting, i.e. 1800-5800 s in figure 6. It can be seen from figure $7(\mathrm{f})$ that the $\mathrm{CO}_{2}$ is saturated at $20 \%$ when the $\mathrm{CN}$ intensities are the highest.

\section{Conclusions}

The recombination of cyanide has been studied in a pilot-scale AC EAF with optical emission spectroscopy combined with camera footage, off-gas data, and electric data of the furnace. The molecular optical emissions of the $\mathrm{CN}$ violet system were clearly observed in the ultra-violet wavelength range and the empirical results show how the $\mathrm{CN}$ intensity changes in different EAF process steps. Several atomic carbon, nitrogen, oxygen, and hydrogen emission lines were also identified from the spectra. Plasma temperature was derived with four O I emission lines, and plasma temperatures with the highest $\mathrm{R}^{2}$ values were observed to be between 4000 and 8000 K. Plasma temperature, electrical input, and interactions between the arc and solid charge material had an apparent effect on the $\mathrm{CN}$ intensities. The industrial applicability of OES measurements has been established in previous studies [19, 22, 23, 32], and the optical emissions from the CN molecule have been observed e.g. in spectra from industrial LF [23].

Analysis of $\mathrm{CN}$ within the wavelength range of this study was found to be viable, whereas molecular optical emissions from other molecules, such as $\mathrm{C}_{2}, \mathrm{~N}_{2}$, and $\mathrm{O}_{2}$, were not detected. Equilibrium composition analyses showed that $\mathrm{CN}$ recombines around $6821 \mathrm{~K}$ in the plasma. Similar calculations resulted in increasing $\mathrm{CN}$ recombination rate as either $\mathrm{C}_{2}, \mathrm{CO}_{2}$, or $\mathrm{CO}$ content of the gas was increased. Molecular optical absorption and emission bands from other molecules than $\mathrm{CN}$ may reside also outside the wavelength range of this study, mainly in the infrared in the case of molecules. Ultraviolet, visible, and near-infrared range, on the other hand, provide beneficial information about the $\mathrm{CN}$ molecule and abundance of atomic optical emissions.

\section{Acknowledgments}

We acknowledge the support of Research Fund for Coal and Steel under grant agreement No. 709 923, Academy of Finland for Genome of Steel grant No. 311 934, Business Finland for grant No. 4478/31/2019, and Steel and Metal Producers' Fund for a 2020 postgraduate grant. We thank Luxmet Oy for the spectrometers and Outotec Oyj for the HSC Chemistry software.

\section{Conflict of interest}

The authors declare that they have no conflict of interest.

\section{ORCID iDs}

Henri Pauna (iD https://orcid.org/0000-0002-6978-8380

Thomas Willms (ib) https://orcid.org/0000-0003-4751-7958

Thomas Echterhof (10 https://orcid.org/0000-0002-5323-2177

Marko Huttula (1) https://orcid.org/0000-0002-4970-598X

Timo Fabritius (i) https://orcid.org/0000-0002-0513-2315

\section{References}

[1] Dash R R, Gaur A and Balomajumder C 2009 Cyanide in industrial wastewaters and its removal: A review on biotreatment J. Hazard. Mater. 163 1-11

[2] Biswas P, Bhunia P, Saha P, Sarkar S, Chandel H and De S 2020 In situ photodecyanation of steel industry wastewater in a pilot scale Environmental Science and Pollution Research $2733226-33$

[3] Ravuru S S, Jana A and De S 2019 Synthesis of nial- layered double hydroxide with nitrate intercalation: Application in cyanide removal from steel industry effluent J. Hazard. Mater. 373 791-800

[4] Dagaut P, Glarborg P and Alzueta M U 2008 The oxidation of hydrogen cyanide and related chemistry Prog. Energy Combust. Sci. 34 $1-46$

[5] Tyagi M, Rana A, Kumari S and Jagadevan S 2018 Adsorptive removal of cyanide from coke oven wastewater onto zero-valent iron: Optimization through response surface methodology, isotherm and kinetic studies J. Clean. Prod. 178 398-407

[6] Moussavi G and Khosravi R 2010 Removal of cyanide from wastewater by adsorption onto pistachio hull wastes: Parametric experiments, kinetics and equilibrium analysis J. Hazard. Mater. 183 724-30

[7] Autelitano F and Giuliani F 2016 Electric arc furnace slags in cement-treated materials for road construction: Mechanical and durability properties Constr. Build. Mater. $113280-9$

[8] Jalkanen H, Kojo M, Krogerus H, Niemelä P and Oikarinen P 1995 Cyanides in FeCr submerged arc furnace production, Theoretical and practical considerations INFACON 7 179-90 
[9] Dong M, Lu J, Yao S, Zhong Z, Li J, Li J and Lu W 2011 Experimental study on the characteristics of molecular emission spectroscopy for the analysis of solid materials containing c and n Opt. Express 19 17021-9

[10] Mousavi S J, Farsani M H, Darbani S M R, Asadorian N, Soltanolkotabi M and Majd A E 2015 Identification of atomic lines and molecular bands of benzene and carbon disulfide liquids by using libs Appl. Opt. 54 1713-20

[11] Fazekas P, Keszler A M, Bódis E, Drotár E, Klébert S, Károly Z and Szépvölgyi J 2014 Optical emission spectra analysis of thermal plasma treatment of poly(vinyl chloride) Open Chemistry 13 549-56

[12] Camacho J J, Díaz L, Santos M, Reyman D and Poyato J M L 2008 Optical emission spectroscopic study of plasma plumes generated by IR CO2pulsed laser on carbon targets J. Phys. D: Appl. Phys. 41105201

[13] Han J-H, Lee T Y, Yoo J-B, Park C-Y, Jung T, Kim J M, Yu S and Yi W 2003 Field emission and growth characteristics of carbon nanotubes with optical emission spectroscopy analysis in c3h4 and co deposition systems Journal of Vacuum Science \& Technology B: Microelectronics and Nanometer Structures Processing, Measurement, and Phenomena 21 1720-6

[14] Firsov A, Savelkin K V, Yarantsev D A and Leonov S B 2015 Plasma-enhanced mixing and flameholding in supersonic flow Philosophical Transactions of the Royal Society A: Mathematical, Physical and Engineering Sciences 37320140337

[15] Li J, Zhu Z, Zhou R, Zhao N, Yi R, Yang X, Li X, Guo L, Zhen X and Lu Y 2017 Determination of carbon content in steels using laserinduced breakdown spectroscopy assisted with laser-induced radical fluorescence Anal. Chem. 89 8134-9

[16] Yao S, Shen Y, Yin K, Pan G and Lu J 2015 Rapidly measuring unburned carbon in fly ash using molecular cn by laser-induced breakdown spectroscopy Energy \& Fuels 29 1257-63

[17] Li X, Yin H, Wang Z, Fu Y, Li Z and Ni W 2015 Quantitative carbon analysis in coal by combining data processing and spatial confinement in laser-induced breakdown spectroscopy Spectrochim. Acta, Part B 111 102-7

[18] Fukushima J and Takizawa H 2018 In situ spectroscopic analysis of the carbothermal reduction process of iron oxides during microwave irradiation Metals 849

[19] Pauna H, Aula M, Seehausen J, Klung J-S, Huttula M and Fabritius T 2020 Optical emission spectroscopy as an on-line analysis method in industrial electric arc furnaces Steel Res. Int. 2000051

[20] Aula M, Demus T, Echterhof T, Huttula M and Fabritius T 2017 On-line analysis of $\mathrm{Cr}_{2} \mathrm{O}_{3}$ content of the slag in pilot scale EAF by measuring optical emission spectrum of electric arc ISIJ Int. 57 478-86

[21] Pauna H, Willms T, Aula M, Echterhof T, Huttula M and Fabritius T 2019 Pilot-scale ac electric arc furnace plasma characterization Plasma Research Express 1035007

[22] Aula M, Leppänen A, Roininen J, Heikkinen E-P, Vallo K, Fabritius T and Huttula M 2014 Characterization of process conditions in industrial stainless steelmaking electric arc furnace using optical emission spectrum measurements Metallurgical and Materials Transactions B 45 839-49

[23] Pauna H, Aula M, Seehausen J, Klung J-S, Huttula M and Fabritius T 2020 Industrial ladle furnace slag composition analysis with optical emissions from the arc ISIJ Int. (https:// doi.org/10.2355/isijinternational.ISIJINT-2019-676)

[24] Valeur B and Berberan-Santos M N 2012 Characteristics of Fluorescence Emission (New York: Wiley)

[25] Jamroz P and Zyrnicki W 2002 Study of the dc and $100 \mathrm{khz}$ glow discharges in acetylene-nitrogen mixture by means of optical emission spectroscopy Eur. Phys. J. AP 19201-9

[26] Kramida A, Ralchenko Y, Reader J and Team N 2020 NIST Atomic Spectra Database (https://doi.org/10.18434/T4W30F)

[27] Aragón C and Aguilera J A 2008 Characterization of laser induced plasmas by optical emission spectroscopy: A review of experiments and methods Spectrochimica Acta Part B 63 893-916

[28] Ovsyannikov A A and Zhukov M F 2000 Plasma Diagnostics (Cambridge: Cambridge International Science Publishers)

[29] Pauna H, Willms T, Aula M, Echterhof T, Huttula M and Fabritius T 2020 Electric arc length-voltage and conductivity characteristics in a pilot-scale ac electric arc furnace Metallurgical and Materials Transactions B 51 1646-55

[30] Parigger C G, Helstern C M and Gautam G 2019 Temporally and spatially resolved emission spectroscopy of hydrogen, cyanide and carbon in laser-induced plasma Atoms 7

[31] Parigger C G, Woods A C, Surmick D M, Gautam G, Witte M J and Hornkohl J O 2015 Computation of diatomic molecular spectra for selected transitions of aluminum monoxide, cyanide, diatomic carbon, and titanium monoxide Spectrochim. Acta, Part B 107 132-8

[32] Aula M, Mäkinen A, Leppänen A, Huttula M and Fabritius T 2015 Optical emission analysis of slag surface conditions and furnace atmosphere during different process stages in electric arc furnace (EAF) ISIJ Int. 55 1702-10 